\title{
In vivo tumour imaging employing regional delivery of novel gallium radiolabelled polymer composites
}

Ross W. Stephens ${ }^{1 *}$ (D), Gregory D. Tredwell', Jessica L. Bell ${ }^{1}$, Karen J. Knox ${ }^{1}$, Lee A. Philip ${ }^{1}$, Tim J. Senden ${ }^{1}$, Michael J. Tapner' ${ }^{2}$ Stephanie A. Bickley², Marcel R. Tanudji and Stephen K. Jones ${ }^{2}$

\begin{abstract}
Background: Understanding the regional vascular delivery of particles to tumour sites is a prerequisite for developing new diagnostic and therapeutic composites for treatment of oncology patients. We describe a novel imageable ${ }^{67} \mathrm{Ga}$-radiolabelled polymer composite that is biocompatible in an animal tumour model and can be used for preclinical imaging investigations of the transit of different sized particles through arterial networks of normal and tumour-bearing organs.

Results: Radiolabelling of polymer microspheres with ${ }^{67} \mathrm{Ga}$ was achieved using a simple mix and wash method, with tannic acid as an immobilising agent. Final in vitro binding yields after autoclaving averaged $94.7 \%$. In vivo stability of the composite was demonstrated in New Zealand white rabbits by intravenous administration, and intrahepatic artery instillations were made in normal and VX2 tumour implanted rabbit livers. Stability of radiolabel was sufficient for rabbit lung and liver imaging over at least 3 hours and 1 hour respectively, with lung retention of radiolabel over 91\%, and retention in both normal and VX2 implanted livers of over 95\%. SPECT-CT imaging of anaesthetised animals and planar imaging of excised livers showed visible accumulation of radiolabel in tumours. Importantly, microsphere administration and complete liver dispersal was more easily achieved with 8 um diameter MS than with $30 \mu \mathrm{m}$ MS, and the smaller microspheres provided more distinct and localised tumour imaging.

Conclusion: This method of producing ${ }^{67} \mathrm{Ga}$-radiolabelled polymer microspheres is suitable for SPECT-CT imaging of the regional vascular delivery of microspheres to tumour sites in animal models. Sharper distinction of model tumours from normal liver was obtained with smaller MS, and tumour resolution may be further improved by the use of ${ }^{68} \mathrm{Ga}$ instead of ${ }^{67} \mathrm{Ga}$, to enable PET imaging.
\end{abstract}

Keywords: Vascular particle delivery, Tumour plexus, Tumour imaging, Radiolabelled polymer microspheres, Rabbit tumour model

\footnotetext{
* Correspondence: ross.stephens@anu.edu.au

${ }^{1}$ The Biomedical Radiochemistry Laboratory, Department of Applied

Mathematics, Research School of Physics, Australian National University,

Canberra, ACT, Australia

Full list of author information is available at the end of the article
}

\section{$\triangle B M C$}

(c) The Author(s). 2021 Open Access This article is licensed under a Creative Commons Attribution 4.0 International License, which permits use, sharing, adaptation, distribution and reproduction in any medium or format, as long as you give appropriate credit to the original author(s) and the source, provide a link to the Creative Commons licence, and indicate if changes were made. The images or other third party material in this article are included in the article's Creative Commons licence, unless indicated otherwise in a credit line to the material. If material is not included in the article's Creative Commons licence and your intended use is not permitted by statutory regulation or exceeds the permitted use, you will need to obtain permission directly from the copyright holder. To view a copy of this licence, visit http://creativecommons.org/licenses/by/4.0/ The Creative Commons Public Domain Dedication waiver (http://creativecommons.org/publicdomain/zero/1.0/) applies to the data made available in this article, unless otherwise stated in a credit line to the data. 


\section{Background}

Understanding the regional vascular delivery of particles to tumour sites is a prerequisite for developing new diagnostic and therapeutic composites for treatment of oncology patients. Clearly this is important in order to predict organ distribution prior to any treatment with particles carrying cytotoxic radioisotopes or toxins. This applies especially to radioisotope treatments with longer half-lives emitting relatively high energy beta emission, such as in selective internal radiation therapy (SIRT) of metastatic colorectal tumours present in the liver [1-3].

We have previously demonstrated liver tumour imaging in animal models using cationised carbon nanoparticles, comprised of a core of ${ }^{99 \mathrm{~m}} \mathrm{Tc}$ encapsulated in graphitic carbon, as a stable electrostatic radiolabel for polymer microspheres (MS) [4]. However, the Gallium isotopes already in clinical use have significant advantages, offering both single-photon emission computed tomography (SPECT) imaging with ${ }^{67} \mathrm{Ga}$ and higher resolution positron emission tomography (PET) imaging with ${ }^{68} \mathrm{Ga}$. Gallium-67 has a physical half-life of $78.3 \mathrm{~h}$ and decays by electron capture, emitting gamma radiation suitable for SPECT imaging. The soluble citrate salt of ${ }^{67} \mathrm{Ga}$ is currently used clinically as an intravenous injection for imaging the extent of Hodgkin's disease, lymphomas and bronchogenic carcinoma [5]. Gallium68 is a positron emitter with a $1.13 \mathrm{~h}$ half-life, but despite this short half-life, the radioisotope can be very useful for PET imaging when produced at the point of use from a ${ }^{68} \mathrm{Ge} /{ }^{68} \mathrm{Ga}$ generator [6-8].

In this report we describe a novel composite comprising ${ }^{67} \mathrm{Ga}$ immobilised on a polymer surface with tannic acid (TA), that has favourable stability in vitro and in vivo for preclinical animal imaging studies. Using SPECT-CT of intact animals, and planar imaging of excised livers, we demonstrate accumulation of MS at tumour sites in livers following arterial administration. We show that tumour accumulation is related to MS size, with smaller $8 \mu \mathrm{m}$ MS producing superior tumour imaging to $30 \mu \mathrm{m}$ MS.

\section{Results}

\section{Synthesis of ${ }^{67} \mathrm{GaTA}-\mathrm{MS}$ and in vitro stability to autoclaving}

Polystyrene sulfonate MS of the same type as used in clinical SIRT [2] were labelled with the radioisotope ${ }^{67} \mathrm{Ga}$ were prepared in a simple, convenient, mix and wash method utilising TA as a stable complexing agent (Fig. 1A). With the strong anion exchange properties of the polystyrene sulfonate, it was straight forward to bind either the chloride or citrate salts of ${ }^{67} \mathrm{Ga}$ in high yields, by mixing with the polymer microsphere in the presence of $\mathrm{HCl}(0.2 \mathrm{M}$ final concentration). The MS were mixed with the radioisotope at room temperature and then washed 3 times with water using centrifugation to collect the MS. The radioisotope was then fixed by mixing with TA $(3 \mathrm{mM})$ at room temperature for $1 \mathrm{~h}$, followed by a further washing step. The MS could then be autoclaved under standard conditions. The bound radioactivity on the MS following each of the binding, fixing and autoclaving steps was high (Fig. 1B), with final yields after autoclaving averaging $94.7 \%$ for both 8 and $30 \mu \mathrm{m}$ diameter MS. Note that this process can also be applied to other metal radioisotopes such as ${ }^{111}$ Indium, ${ }^{201}$ Thallium, ${ }^{177}$ Lutetium, and ${ }^{90}$ Yttrium, with high binding yields (Fig. 1C, unoptimised yields).

\section{Leach tests of ${ }^{67} \mathrm{GaTA}-\mathrm{MS}$ stability by entrapment in normal rabbit lungs}

The in vivo stability of the ${ }^{67}$ GaTA-MS preparations was tested by intravenous injection into the lungs of rabbits. Using less than $5 \mathrm{mg}$ MS per $\mathrm{kg}$ of body weight, there was no apparent change in breathing over the $3 \mathrm{~h}$ postinjection test period. Suspensions of ${ }^{67}$ GaTA-MS30 and ${ }^{67}$ GaTA-MS8 were retained well in the vascular network of the lungs over $3 \mathrm{~h}$, as shown by gamma camera imaging of the anaesthetised animals (Fig. 2A and B, respectively), compared with intravenous injection of soluble ${ }^{67} \mathrm{Ga}$ (Fig. 2C). After $3 \mathrm{~h}$ the animals were euthanised, and the lungs, livers and body were imaged separately for more quantitative radioactivity biodistribution data (Table 1). For ${ }^{67}$ GaTA-MS30, the average proportion of radioactivity retained in the lungs was $97.3 \pm$ $0.4 \%$ of the total body activity, and only $0.61 \pm 0.1 \%$ was present in the excised liver. For ${ }^{67}$ GaTA-MS8, the average proportion of radioactivity retained in the lungs was slightly lower at $91.1 \pm 0.4 \%$ of the total body activity, and with $1.5 \pm 0.3 \%$ present in the liver. For comparison, rabbits injected with soluble ${ }^{67} \mathrm{Ga}$ had low lung and liver radioactivity with only 5.3 and $9.9 \%$, respectively, of the total body radioactivity (Fig. $2 \mathrm{C}$ and Table 1 ).

\section{Biodistribution of ${ }^{67} \mathrm{GaTA}-\mathrm{MS}$ in normal rabbit livers} Suspensions of both the ${ }^{67}$ GaTA-MS30 and ${ }^{67}$ GaTAMS8 were administered to rabbit livers via the hepatic artery. Some administration failures were encountered with the larger ${ }^{67}$ GaTA-MS30, when the MS remained predominantly at a central part of the liver and did not disperse widely in the organ. There were no administration failures when using the smaller ${ }^{67}$ GaTA-MS8. Planar gamma imaging of anaesthetised animals showed virtually complete retention of the radiolabel in the liver, and after $1 \mathrm{~h}$ following administration the animals were euthanised and the lungs and liver were dissected to obtain more quantitative radioactivity biodistribution (Table 2). Normal rabbit liver radioactivity when instilled with the ${ }^{67} \mathrm{GaTA}-\mathrm{MS} 30$ composites was an average $98.9 \pm 0.3 \%$ of the total body radioactivity, and lung 
A

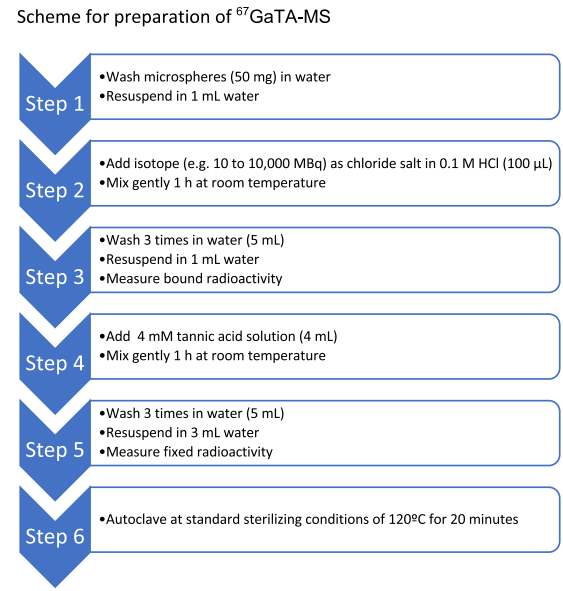

B

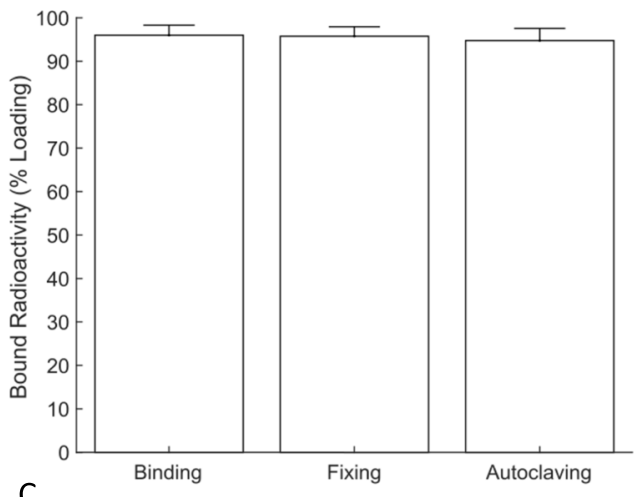

C

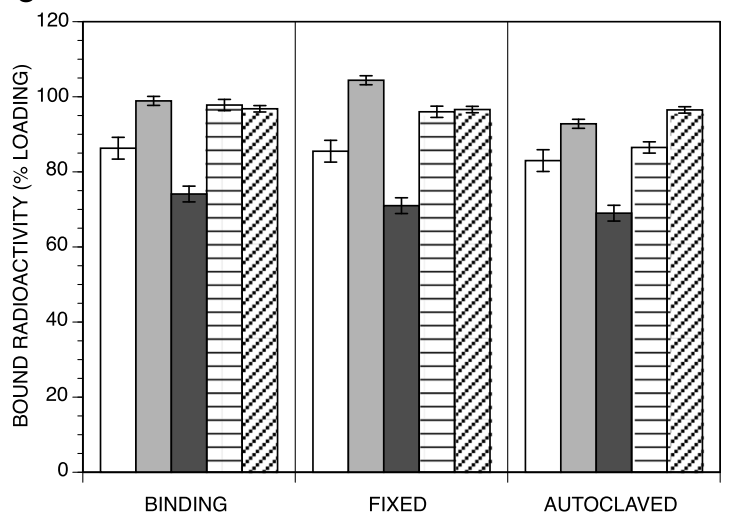

Fig. 1 Radiolabelling method for polymer MS. a Step by step scheme for the preparation of ${ }^{67} \mathrm{GaTA}-\mathrm{MS}$, starting from an example amount of $50 \mathrm{mg}$ of sulfonated polystyrene MS. b Optimised radiolabelling binding efficiency of ${ }^{67} \mathrm{Ga}$ on both $8 \mu \mathrm{m}$ and $30 \mu \mathrm{m}$ diameter MS ( $n=12, n=5$, respectively. Data combined). The bound fraction of each isotope loading is shown after the initial binding step (Binding), after the step with TA treatment (Fixed) and after autoclaving (Autoclaved); c A comparison of unoptimized microsphere radiolabelling binding efficiency for five different radionuclides. Polystyrene sulfonate MS $(50 \mathrm{mg}, 30$ um median diameter) was radiolabelled with (columns from left to right) ${ }^{67} \mathrm{Ga}$ (100-200 MBq; $n=14)$, In-111 (34 MBq; $n=2)$, TI-201 (93 MBq; $n=2)$, Lu-177 (50-150 MBq; $n=7)$ and Y-90 (42 MBq; $n=2)$. The bound fraction of each radionuclide loading is shown after the initial binding step (Binding), after the step with TA treatment (Fixed) and after autoclaving (Autoclaved)

activity was only $0.07 \pm 0.03 \%$. With ${ }^{67}$ GaTA-MS8, the mean liver activity was slightly lower at $95.2 \pm 2.4 \%$, and the lung activity $0.57 \pm 0.35 \%$ of the total body radioactivity. In comparison, soluble ${ }^{67} \mathrm{Ga}$ displayed no appreciable affinity for either the liver or lungs, with mean radioactivity of 15.4 and $4.7 \%$, respectively, of the total body radioactivity. Images of the excised livers revealed a pronounced difference in the distribution for the 2 different diameters of MS, ${ }^{67} \mathrm{GaTA}-\mathrm{MS} 30$ and ${ }^{67} \mathrm{GaTA}$ MS8 (Fig. 3A and B, respectively). Livers instilled with ${ }^{67}$ GaTA-MS30 did not have radioactivity extending throughout the organ, but instead it appeared to have been arrested at limiting diameters of the arterial network, displaying a course tree-like structure. The image shown in Fig. 3A was the best liver dispersal obtained for ${ }^{67} \mathrm{GaTA}-\mathrm{MS} 30$. In contrast, the smaller diameter ${ }^{67}$ GaTA-MS8 routinely dispersed well within the liver and displayed a much finer liver distribution (Fig. 3B), being able to disperse to the finer arterial vessels throughout the whole tissue, while still not being able to pass through the microcapillaries to the venous collection. The soluble ${ }^{67} \mathrm{Ga}$ instilled intra-arterially in the liver displayed no appreciable retention in the liver, and was distributed systemically throughout the rabbit (Fig. $3 \mathrm{C}$ and Table 2).

\section{Biodistribution of ${ }^{67} \mathrm{GaTA}-\mathrm{MS}$ in rabbit livers with implanted VX2 tumours}

Implantation of rabbit livers with small pieces of VX2 tumours was performed using sterile keyhole surgery on a single site on one lobe, and after 18-21 days of growth, tumours appeared macroscopically on dissection as a single oblate ellipsoid of up to $2 \mathrm{~cm}$ diameter. Intraarterial instillations of ${ }^{67}$ GaTA-MS30 and ${ }^{67}$ GaTA-MS8 were then made in these rabbit livers hosting grown VX2 tumour implants. SPECT-CT imaging of the intact animals showed good retention of both sizes of MS in the liver (Fig. 4). Within the liver, ${ }^{67}$ GaTA-MS30 showed isotope activity mainly in the right lobe hosting the 


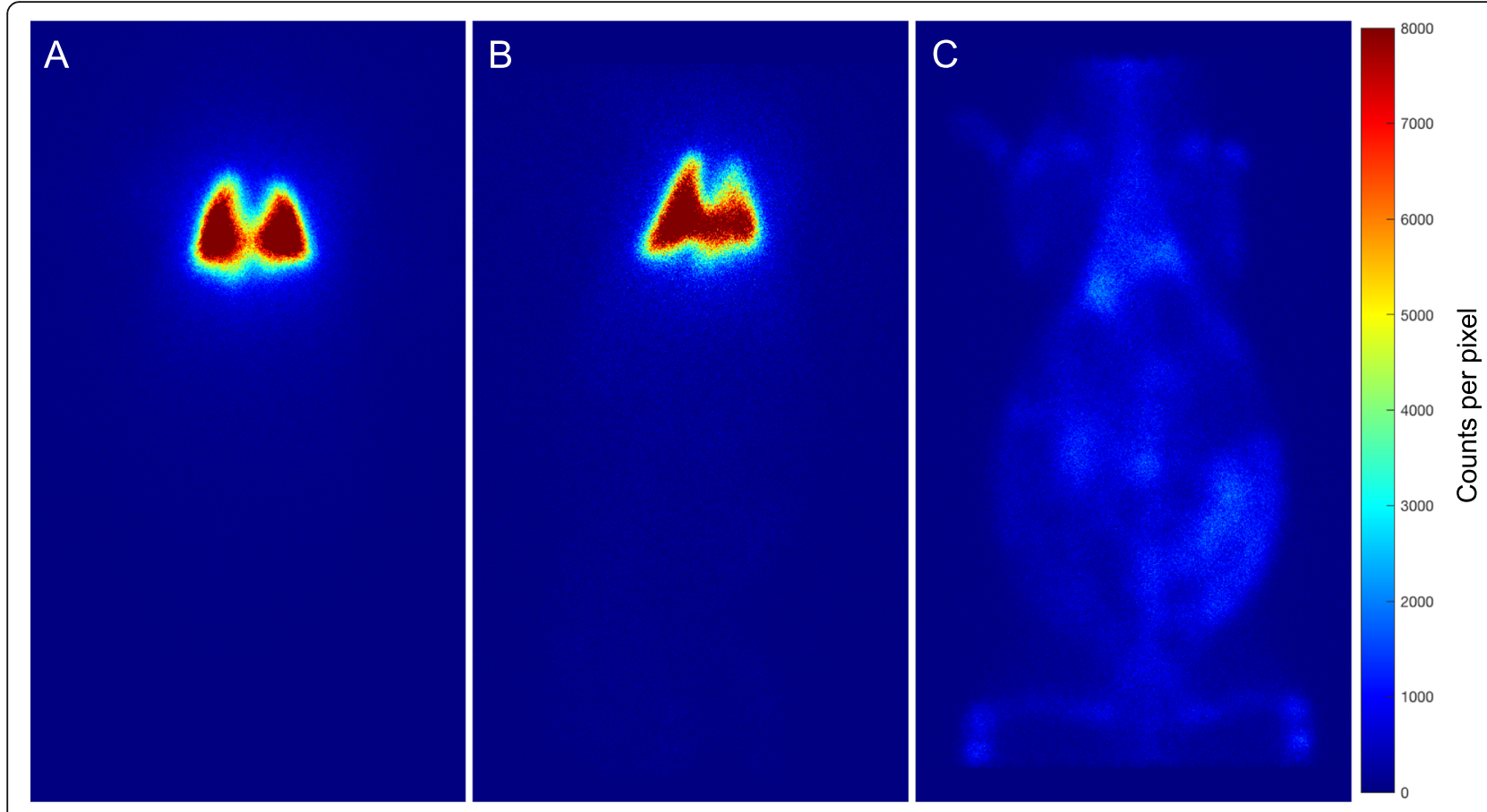

Fig. 2 Leach tests of ${ }^{67} \mathrm{Ga}$ labelled MS in normal rabbit lungs. Polystyrene sulfonate MS (15 mg, $30 \mu \mathrm{m}$ and $8 \mu \mathrm{m}$ median diameter) were radiolabelled with ${ }^{67} \mathrm{Ga}$ (avg. $87 \mathrm{MBq}$ ) using TA immobilisation. The suspensions in 5\% dextrose (5 mL) were injected intravenously (ear vein) into anaesthetised rabbits and planar images of the rabbits were made $3 \mathrm{~h}$ post-injection using a GE Hawkeye Infinia SPECT-CT camera with a medium energy collimator and scatter correction. Control rabbits were injected intravenously with soluble ${ }^{67} \mathrm{Ga}$ (avg. $87 \mathrm{MBq}$ ) for comparison of the biodistribution. Note pronounced lung retention of radiolabel using both ${ }^{67} \mathrm{GaTA}-\mathrm{MS} 30$ (a) and ${ }^{67} \mathrm{GaTA}-\mathrm{MS} 8(\mathbf{b})$, while soluble ${ }^{67} \mathrm{Ga}$ citrate was systemically distributed with no lung definition (c)

tumour, as seen in the left side of the coronal image and in the left side of the transaxial image in Fig. 4A. However, there was significant activity in the rest of the liver, as seen in the right side of the coronal image and in the right side of the transaxial image in Fig. 4A. Importantly, using the smaller ${ }^{67}$ GaTA-MS8, accumulation of isotope appeared more localised to the single tumour site in the implanted lobe, as seen in the corresponding images of Fig. 4B.

This result was confirmed by excising the livers from the same rabbits and making planar images, when it was apparent that while both ${ }^{67}$ GaTA-MS30 and ${ }^{67}$ GaTA-

Table 1 Leach Tests for ${ }^{67} \mathrm{Ga}$ Labelled MS in Rabbit Lungs

\begin{tabular}{lllll}
\hline Isotope Form & No. of Tests & $\begin{array}{l}\text { Lungs } \\
\text { [\%Total] }\end{array}$ & $\begin{array}{l}\text { Liver } \\
\text { [\%Total] }\end{array}$ & $\begin{array}{l}\text { Body } \\
\text { [\%Total] }\end{array}$ \\
\hline MS30 & 5 & $97.3 \pm 0.4$ & $0.61 \pm 0.1$ & $2.5 \pm 0.3$ \\
MS8 & 3 & $91.1 \pm 0.4$ & $1.5 \pm 0.3$ & $7.3 \pm 0.7$ \\
Soluble & 2 & $5.3 \pm 0.4$ & $9.9 \pm 0.7$ & $83.4 \pm 0.3$ \\
\hline
\end{tabular}

Polystyrene sulfonate MS ( $15 \mathrm{mg}, 30 \mu \mathrm{m}$ and $8 \mu \mathrm{m}$ median diameter) were radiolabelled with ${ }^{67} \mathrm{Ga}$ (avg. $87 \mathrm{MBq}$ ) using TA immobilisation. Suspensions of the MS in $5 \%$ dextrose $(5 \mathrm{~mL}$ ) were injected intravenously (ear vein) into anaesthetised rabbits. Intravenous injection of soluble ${ }^{67} \mathrm{Ga}$ (avg. $87 \mathrm{MBq}$ ) was also performed to provide a comparison of the biodistribution. The rabbits were euthanized after $3 \mathrm{~h}$ for dissection and gamma camera imaging of lungs, liver, and body. The activities of all images were corrected for background and the activity of each organ expressed as a percentage of the total activity
MS8 displayed a noticeable accumulation of the label at the tumour site (Fig. 5A and B respectively), the smaller diameter ${ }^{67}$ GaTA-MS8 had a more pronounced tumour accumulation, appearing in planar imaging as a sharply defined circular feature of high activity (Fig. 5B). In lobes that did not contain the VX2 tumour, ${ }^{67}$ GaTA-MS30 displayed a coarse tree-like structure for the distribution of the radiolabel, and some normal liver tissue areas had significant radioactivity (Fig. 5A). By contrast, livers instilled with the smaller ${ }^{67} \mathrm{GaTA}-\mathrm{MS} 8$ had lower intensities of radioactivity in normal lobes Fig. 5B), presumably due to volumetric dilution by more extensive dispersal throughout the tissue via finer blood vessels. Importantly, this was not accompanied by escape of the ${ }^{67}$ GaTA-MS8 from VX2 implanted livers into the systemic circulation; $1 \mathrm{~h}$ following intraarterial instillation $95.2 \pm 2.4 \%$ of the total body radioactivity was still present in the liver (Table 2). By contrast, instillation of soluble ${ }^{67} \mathrm{Ga}$ did not produce any discernible liver or tumour retention, with only $4.5 \pm$ $1.0 \%$ of the total body radioactivity remaining in the organ (Fig. 5C and Table 2).

\section{Discussion}

This article describes a novel method for radiolabelling polymer MS with Gallium isotopes, employing a simple, 
Table 2 Retention of ${ }^{67} \mathrm{Ga}$ Labelled MS in Rabbit Livers with and without Implants of VX2 tumours

\begin{tabular}{llllll}
\hline Organ Test & $\begin{array}{l}\text { MS Diameter } \\
{[\mu \mathrm{m}]}\end{array}$ & No. of Tests & $\begin{array}{l}\text { Lungs } \\
{[\% \text { Total] }}\end{array}$ & $\begin{array}{l}\text { Liver } \\
{[\% \text { Total] }}\end{array}$ & $\begin{array}{l}\text { Body } \\
{[\% \text { Total] }}\end{array}$ \\
\hline Normal Liver & 30 & 3 & $0.07 \pm 0.03$ & $98.9 \pm 0.3$ & $0.97 \pm 0.23$ \\
& 8 & 2 & $0.57 \pm 0.35$ & $95.2 \pm 2.4$ & $4.1 \pm 2.0$ \\
& Soluble & 2 & $4.7 \pm 0$ & $15.4 \pm 3.0$ & $78.1 \pm 3.2$ \\
VX2 Liver & 30 & 2 & $0.02 \pm 0.03$ & $99.2 \pm 0.2$ & $0.78 \pm 0.18$ \\
& 8 & 4 & $0.62 \pm 0.07$ & $95.7 \pm 0.5$ & $3.5 \pm 0.5$ \\
& Soluble & 2 & $1.83 \pm 0.13$ & $4.5 \pm 1.0$ & $93.1 \pm 0.95$
\end{tabular}

Polystyrene sulfonate MS ( $15 \mathrm{mg}, 30 \mu \mathrm{m}$ and $8 \mu \mathrm{m}$ median diameter) were radiolabelled with ${ }^{67} \mathrm{Ga}$ (avg. $\left.110 \mathrm{MBq}\right)$ using TA immobilisation. Suspensions of the MS in $5 \%$ dextrose $\left(5 \mathrm{~mL}\right.$ ) were instilled into the hepatic artery of anaesthetised rabbits. Instillation of soluble ${ }^{67} \mathrm{Ga}$ (avg. $110 \mathrm{MBq}$ ) was also performed to provide a comparison of the biodistribution. The rabbits were euthanized after $1 \mathrm{~h}$ for dissection and gamma camera imaging of lungs, liver, and body. The activities of all images were corrected for background and the activity of each organ expressed as a percentage of the total activity. Note pronounced liver retention of radiolabel using both ${ }^{67} \mathrm{GaTA}-\mathrm{MS} 30$ and ${ }^{67} \mathrm{GaTA}-\mathrm{MS} 8$ compared to liver retention of soluble ${ }^{67} \mathrm{Ga}$. Retention of microsphere radiolabel in livers with VX2 tumour implants was indistinguishable from retention by normal livers

convenient mix and wash method requiring no special equipment. A product with high radiopurity that is stable to autoclave sterilisation can be obtained with minimal handling. The product has utility in imaging regional vascular delivery of polymer MS to tumour sites, as demonstrated here in a rabbit liver tumour model. Preliminary indications of biocompatibility were seen in this animal model setting. Importantly, the results show that smaller MS have superior administration, dispersal and tumour imaging properties.

Gallium isotopes can be considered the preferred choice for making imageable polymer particles that can be used to predict biodistribution of the corresponding therapeutic particles in organs hosting tumours. Gallium-67 citrate with its relatively long half-life of $78.3 \mathrm{~h}$ is already a current clinical product for SPECT imaging of patients with Hodgkin's disease [5], lymphomas and bronchogenic carcinoma. In our method, by simply adjusting the $\mathrm{pH}$ with $1 \mathrm{M} \mathrm{HCl}$, the ${ }^{67} \mathrm{Ga}^{3+}$ ions could be dissociated from the citrate complex and bound readily to polystyrene sulfonate $\mathrm{MS}$, which has the properties of a strong cation exchange resin. A stable radioisotope complex is then simply formed by addition of TA, and the method does not require the use of any special equipment. Clearly, it would be straight-forward to adapt this method to ${ }^{68} \mathrm{Ga}$ eluted from a commercially available germanium-68/Gallium-68 generator. The radioisotope eluted with hydrochloric acid could be directly bound to the MS in a single step enabling PET imaging with the final radiolabelled MS. Furthermore, we have applied this method to other metal radioisotopes such as ${ }^{111}$ Indium, ${ }^{201}$ Thallium, ${ }^{177}$ Lutetium, and ${ }^{90}$ Yttrium, with high binding yields.

Tannins, a class of astringent, polyphenolic biomolecules, are major constituents of our beverages and food stuffs [9], so they are known to be biocompatible. The metal ion chelation properties of TA are well known, and the phenolic-metal ion complexes are often coloured [10]. It is believed that the highly stable complexes of Fe (III) with TA are not bioavailable [9], and in

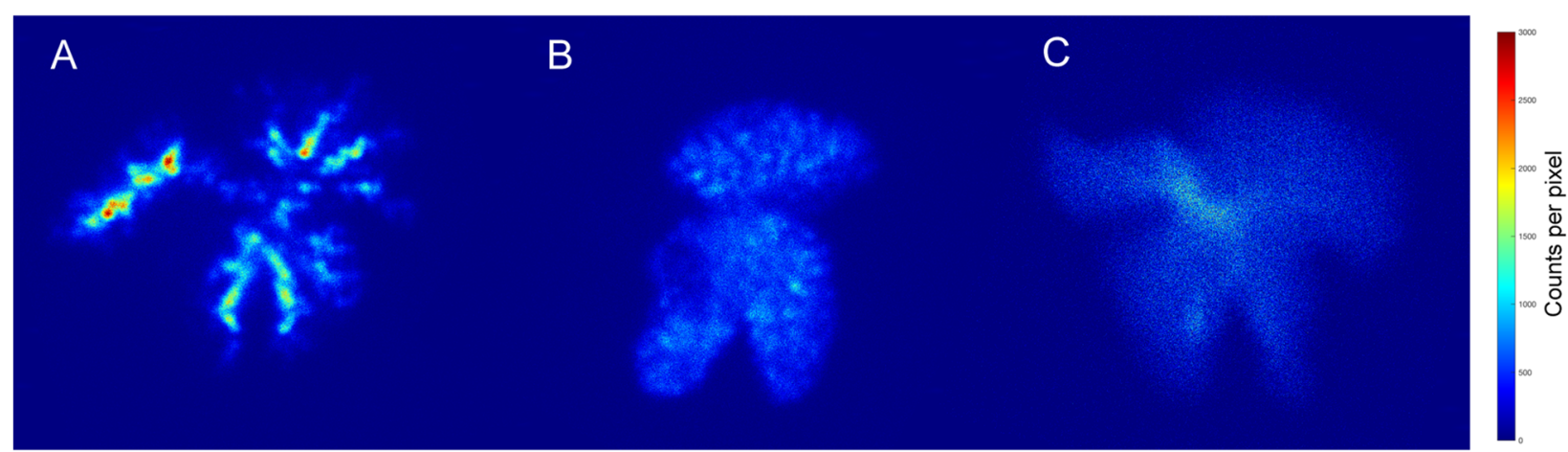

Fig. 3 Retention of ${ }^{67} \mathrm{Ga}$ labelled MS in normal rabbit livers. Polystyrene sulfonate MS (40 mg, $30 \mu \mathrm{m}$ and $8 \mu \mathrm{m}$ median diameter) were radiolabelled with ${ }^{67} \mathrm{Ga}$ (avg. $110 \mathrm{MBq}$ ) using TA immobilisation. The suspensions in $5 \%$ dextrose $(5 \mathrm{~mL}$ ) were instilled into the hepatic artery of anaesthetised rabbits and planar images of excised livers were made $1 \mathrm{~h}$ post-injection using a GE Hawkeye Infinia SPECT/CT camera with a medium energy collimator and scatter correction. Soluble ${ }^{67} \mathrm{Ga}$ citrate (avg. $110 \mathrm{MBq}$ ) was instilled into hepatic arteries of control rabbits for comparison with the retention of microspheres. Note the prominent vessel features and less extensive volume filling of the liver obtained with ${ }^{67} \mathrm{GaTA}-\mathrm{MS} 30$ (a), compared to the more extensively dispersed fine network obtained with ${ }^{67} \mathrm{GaTA}-\mathrm{MS} 8$ (b). Under the same conditions, soluble ${ }^{67} \mathrm{Ga}$ citrate was mostly purged from the liver by the normal blood perfusion (c) 

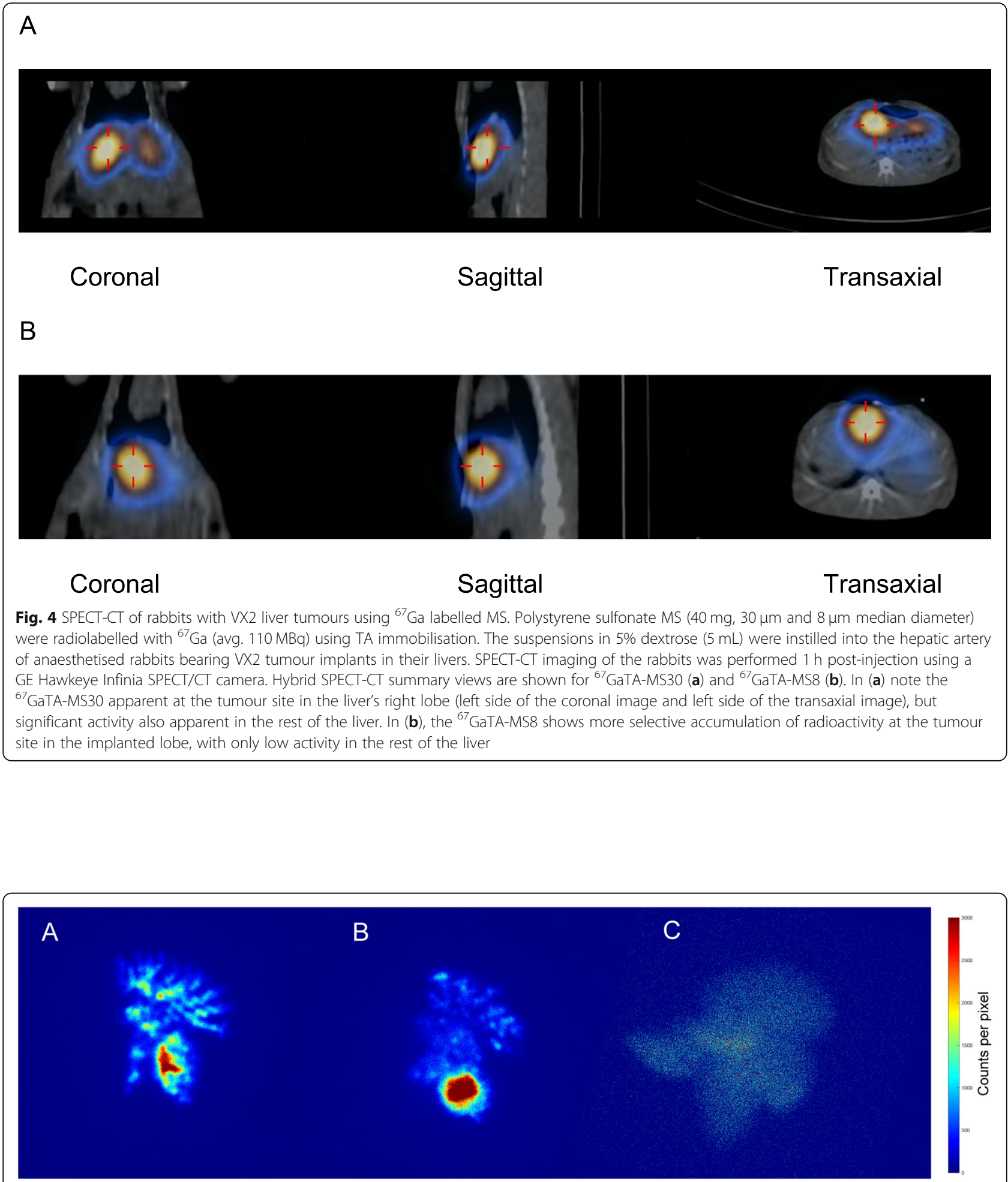

Fig. 5 Planar imaging of excised livers with VX2 tumours. The same rabbits shown in Fig. 4A and B above were dissected to enable planar imaging of their livers. As in Fig. 3 above for normal livers, note the prominent vessel features and less extensive volume filling of the liver obtained with ${ }^{67} \mathrm{GaTA}-\mathrm{MS} 30$ (a), compared to the more extensively dispersed fine network obtained with ${ }^{67} \mathrm{GaTA}$-MS8 (b). Importantly, while the tumour site in (a) was identifiable, having increased activity compared to the rest of the liver, the use of ${ }^{67}$ GaTA-MS8 in (b) revealed a more sharply distinct tumour site of high activity, with only weak activity in the rest of the liver. For comparison, the excised liver from a rabbit instilled with soluble ${ }^{67} \mathrm{Ga}$ citrate showed extensive loss of isotope from the organ, and although a tumour was present in this liver, there was no appreciable tumour retention of isotope (c) 
fact consumption of large quantities of tannin-rich foods is sometimes associated with iron-deficiency anemia [11]

Free Gallium in the blood acts as an iron analogue, binding to the plasma protein transferrin. A strong interaction between Gallium and TA is therefore likely and important for minimising unwanted organ uptake by interfering with interactions of Gallium with plasma proteins. As was observed for a patient treated with deferoxamine prior to ${ }^{67} \mathrm{Ga}$-citrate scintigraphy demonstrating an altered biodistribution of Gallium [12].

Previously described methods for immobilising radioisotopes such as ${ }^{67} \mathrm{Ga}$ have involved the preparation of covalently linked macrocyclic ligands such as DOTA and NOTA. While DOTA is the mostly used chelator, the smaller, tri-chelator, NOTA was found to bind Gallium better $[13,14]$. In this method the TA is not covalently bound to the MS, but instead forms a stable complex involving both the Gallium ion and the polystyrene sulfonate surface.

This complex is stable to autoclave conditions and the radiolabelled MS were stable for $3 \mathrm{~h}$ in vivo following intravenous delivery to the lungs of New Zealand white rabbits. Furthermore, hepatic artery administration of the ${ }^{67}$ GaTA-MS showed very efficient retention of the radiolabel at limiting diameters of the liver arterial network. As was observed for the Tc99m labelled MS that we described earlier [4], the smaller diameter ${ }^{67}$ GaTAMS8 displayed a much finer liver distribution, dispersing more extensively into the vascular network than the larger ${ }^{67} \mathrm{GaTA}-\mathrm{MS} 30$, which tended to define a jagged, tree-like pattern of the larger vessels.

For rabbits with implanted VX2 tumours, there was no significant evidence of hepatopulmonary or hepatogastric shunting, and retention of radiolabel within livers hosting a tumour was maintained at a very high level. Images of livers implanted with VX2 tumours demonstrated that the tumours had remodelled the local arterial supply, producing a bias of distribution and accumulation of radiolabelled MS in tumours, as seen before in computed tomography studies [15]; this was evident for both sizes of MS tested. However, the smaller MS produced a more defined image of tumours, presumably due to its ability to penetrate further into the plexus of abnormally tortuous angiogenic vessels in the tumour microenvironment [16], while still being large enough not to transit to the venous collection and enter the systemic circulation. Our study of $8 \mu \mathrm{m}$ MS extends further downward the range of MS size reported previously [17], when more extensive imaging of VX2 vascular networks was obtained with $30 \mu \mathrm{m}$ than with $100 \mu \mathrm{m}$ MS. It is evident that the tumour plexus, consistent with the observed increase in flow resistance [18], tends to behave as a labyrinthine trap that limits transit of non-deformable polymer particles, even those comparable in size to deformable blood cells. Blood cells, especially erythrocytes, are well known [19] to traverse capillaries by deforming to a smaller crosssection, whereas non-deformable particles of similar size to blood cells will not traverse capillaries.

\section{Conclusion}

We have now demonstrated tumour imaging results for different sizes of 2 types of polymer MS preparations, radiolabelled by the use of 2 completely different labelling chemistries and 2 different radioisotopes, i.e. ${ }^{99 \mathrm{~m}} \mathrm{Tc}$-nanoparticle radiolabelled MS [4] and ${ }^{67} \mathrm{GaTA}$ MS. The consistent message is that smaller MS, even down to $8 \mu \mathrm{m}$ diameter, produce better tumour definition in imaging, and without appreciable leakage to the systemic circulation. The increased ability of smaller radiolabelled MS to highlight tumours in imaging is informative for scoping the location, size and number of tumours in an organ, and potentially also useful as an indicator of reduced tumour perfusion achieved by angiogenesis inhibitors. All these results assist in evaluating accessibility of solid tumours to therapeutic MS and the likelihood of achieving a therapeutic impact. Considerable further work is required however at the preclinical level to specifically address the biocompatibility, toxicology and clearance of this novel composite.

\section{Materials and methods}

Stable labelling of MS with ${ }^{67} \mathrm{Ga}$

Polystyrene sulfonate MS of the same type as used in clinical SIRT [2] and of two different sizes were used in this study; $30 \mu \mathrm{m}$ (MS30), and $8 \mu \mathrm{m}$ (MS8) median diameter (Sirtex Medical Ltd., Sydney). The radioisotope

${ }^{67} \mathrm{Ga}$ was obtained as an aqueous citrate salt from Global Medical Solutions Australia. USP grade TA was purchased from Sigma-Aldrich (Sydney, Australia). Radiolabelled ${ }^{67} \mathrm{Ga}$ MS were prepared as previously described [20] and summarised in Fig. 1A. Briefly, MS (15-40 mg) were first washed 3 times with water $(5 \mathrm{~mL})$ using centrifugation at $350 \mathrm{~g}$ for $2 \mathrm{~min}$. The MS were then mixed for $1 \mathrm{~h}$ with ${ }^{67} \mathrm{Ga}$-citrate and $1 \mathrm{M} \mathrm{HCl}(1 \mathrm{~mL})$ in a final volume of $5 \mathrm{~mL}$ water. After washing 3 times using centrifugation ( $350 \mathrm{~g}, 2 \mathrm{~min}$ ), the MS were then resuspended in $3 \mathrm{mM}$ TA $(5 \mathrm{~mL})$ for $1 \mathrm{~h}$. After 3 further washes with water, the MS were resuspended in water $(3 \mathrm{~mL})$ and autoclaved at $120^{\circ} \mathrm{C}$ for $20 \mathrm{~min}$ to give the radiolabelled product.

\section{Leach tests of ${ }^{67} \mathrm{Ga}$ labelled MS $\left({ }^{67} \mathrm{GaTA}\right.$-MS) in normal rabbit lungs}

All rabbit procedures adhered to the National Health and Medical Research Council's Australian code for the care and use of animals for scientific purposes (Australian Government, 8th Ed., 2013), and the experimental 
protocols were approved by the Australian National University (ANU) Animal Ethics Committee. Rabbit imaging studies were carried out using intubation to deliver ventilation anaesthesia with isoflurane, so that biodistribution of the radiolabel in live animals could be followed for up to $3 \mathrm{~h}$. Imaging of the anaesthetised rabbits, and their excised organs after $3 \mathrm{~h}$, was performed with a Hawkeye Infinia SPECT-CT camera (GE Healthcare). Images were obtained using a medium energy collimator with energy emission windows of $93 \pm 13,184 \pm 10$, and $300 \pm 10 \mathrm{keV}$, and Compton scatter correction windows of $75 \pm 7$, and $140 \pm 10 \mathrm{keV}$. To test the lung retention of the radiolabelled MS, suspensions of ${ }^{67}$ GaTA-MS30 and ${ }^{67}$ GaTA-MS8 (avg. $87 \mathrm{MBq}$ on $15 \mathrm{mg}$ MS in $5 \mathrm{~mL} 5 \%$ dextrose) were injected intravenously into an ear vein, so that the MS were mechanically arrested at limiting diameters in the arterial network of the lungs. Static $5 \mathrm{~min}$ acquisitions were made on a $1024 \times 1024$ matrix, approx. 10 min after injection of the MS and again every hour up to $3 \mathrm{~h}$, before the rabbits were euthanized by lethal injection while still under anaesthesia. The lungs and liver were then excised after tying off blood vessels to prevent leakage of the radioisotope, and the excised organs were imaged separately using a 5 min acquisition on a $1024 \times 1024$ matrix and utilising the camera's zoom function $(4 \times)$. Counts registered in the acquisitions were corrected for the background activity of the corresponding field, and the corrected counts were used for calculation of the percentage activity in the lungs, liver, and body. The DICOM image files were read into MATLAB (MathWorks, MA, USA) and were scaled such that the total counts of individual images were equal.

\section{Arterial distribution of ${ }^{67} \mathrm{GaTA}-\mathrm{MS}$ in normal rabbit livers} Intrahepatic artery instillations of ${ }^{67}$ GaTA-MS30, ${ }^{67} \mathrm{GaTA}-\mathrm{MS} 8$ (40 mg each) and soluble ${ }^{67} \mathrm{Ga}$-citrate were performed by catheterisation of the cystic artery and using pulses of the particle suspension (total $5 \mathrm{~mL} \mathrm{5 \%}$ dextrose, avg. $110 \mathrm{MBq}$ ) interspaced with normal hepatic artery blood flow, so as to disperse the radiolabelled material throughout the liver with close to normal arterial blood perfusion conditions [21]. The MS were kept suspended by gentle agitation during instillation. Static 5 min acquisitions were made on a $1024 \times 1024$ matrix, approx. $10 \mathrm{~min}$ after administration of the imaging agent and again after 1 hour, before the rabbits were euthanised by lethal injection while still under anaesthesia. The lungs and liver were excised after tying off blood vessels to prevent leakage of the radioisotope, and the excised organs were imaged separately using a $5 \mathrm{~min}$ acquisition on a $1024 \times 1024$ matrix and utilising the zoom function. Counts registered in the acquisitions were corrected for the background activity of the corresponding field, and the corrected counts were used for calculation of the percentage activity in the organs. The DICOM image files were read into MATLAB (MathWorks, MA, USA) and for each of the images the individual pixel counts were divided by the total image counts and then scaled by a constant factor.

\section{Imaging of the rabbit VX2 liver tumour model}

The transplantable rabbit VX2 tumour [22] was a kind gift of Dr. J Geschwind (Johns Hopkins University, Baltimore, USA) and was maintained as a serial transplant on the hind limbs of New Zealand white rabbits. Liver implants of small pieces of tumour tissue were made at a single site in one lobe by keyhole surgery under ventilation anaesthesia with isoflurane and allowed to grow for 18-21 days before use of the rabbit in imaging experiments. At this stage of growth, the tumour was an oblate ellipsoid of maximum diameter 2 $\mathrm{cm}$, still contained within the liver lobe and not involving the body wall or other organs. Macroscopically, the tumour usually had a white necrotic centre, surrounded by a prominently vascularised peripheral growth zone. Intrahepatic artery instillations of ${ }^{67} \mathrm{GaTA}-\mathrm{MS} 30$ and ${ }^{67}$ GaTA-MS8 (40 mg each) were made in the livers hosting tumours as above and SPECT-CT imaging with a Hawkeye Infinia camera was performed $1 \mathrm{~h}$ post instillation, before the rabbits were euthanised by lethal injection while still under anaesthesia. The lungs and liver were excised after tying off blood vessels to prevent leakage of the radioisotope, and planar images of the excised organs were made separately using a $5 \mathrm{~min}$ acquisition on a $1024 \times 1024$ matrix and utilising the zoom function. Counts registered in the acquisitions were corrected for the background activity of the corresponding field, and the corrected counts were used for calculation of the percentage activity in the organs. The DICOM image files were read into MATLAB (MathWorks, MA, USA) and for each of the images the individual pixel counts were divided by the total image counts and then scaled by a constant factor.

\section{Abbreviations}

MS: Polystyrene sulfonate microsphere; PET: Positron emission tomography; SIRT: Selective internal radiation therapy; SPECT: Single-photon emission computed tomography; TA: Tannic acid; ${ }^{67} \mathrm{GaTA}-\mathrm{MS} 8:{ }^{67} \mathrm{Ga}$ labelled MS of 8 m diameter; ${ }^{67} \mathrm{GaTA}$ MS30: ${ }^{67} \mathrm{Ga}$ labelled MS of $30 \mu \mathrm{m}$ diameter

\section{Acknowledgements}

The ANU authors acknowledge the collaborative research project support generously provided to ANU by Sirtex Medical Ltd. (Sydney), including donation of a GE Hawkeye Infinia SPECT/CT scanner and a Xeleris image processing system.

\section{Authors' contributions}

The radioisotope preparations and animal investigations were performed at the Biomedical Radiochemistry Laboratory by GDT, JLB, KJK and LAP under the direction of RWS and with advice from TJS. MJT, SAB, MRT and SKJ provided supporting logistics, materials and technical advice. GDT analysed the results. The manuscript was written by RWS and GDT. The authors read and approved the final manuscript. 


\section{Funding}

The ANU authors acknowledge the collaborative research project support generously provided to ANU by Sirtex Medical Ltd. (Sydney), including donation of a GE Hawkeye Infinia SPECT/CT scanner and a Xeleris image processing system.

\section{Availability of data and materials}

The datasets generated during and/or analysed during the current study are available from the corresponding author on reasonable request.

\section{Declarations}

\section{Ethics approval}

All rabbit procedures adhered to the National Health and Medical Research Council's Australian code for the care and use of animals for scientific purposes (Australian Government, 8th Ed., 2013), and the experimental protocols were approved by the ANU Animal Ethics Committee.

\section{Consent for publication}

The corresponding author (RWS) has the permission of all co-authors.

\section{Competing interests}

MJT, SAB, MRT, and SKJ were employees of Sirtex Medical Ltd. at the time this investigational research was performed by JLB, KJK, LAP and GDT at the ANU's Biomedical Radiochemistry Laboratory under the direction of RWS.

\section{Author details}

${ }^{1}$ The Biomedical Radiochemistry Laboratory, Department of Applied Mathematics, Research School of Physics, Australian National University, Canberra, ACT, Australia. ${ }^{2}$ Sirtex Medical Ltd, Sydney, Australia.

\section{Received: 24 January 2021 Accepted: 16 March 2021}

Published online: 31 March 2021

\section{References}

1. Gray BN, Anderson JE, Burton MA, Van Hazel G, Codde J, Morgan C, et al. Regression of liver metastases following treatment with yttrium-90 microspheres. Aust NZ J Surg. 1992;62:105-10.

2. Kucuk ON, Soydal C, Lacin S, Ozkan E, Bilgic S. Selective intraarterial radionuclide therapy with Yttrium-90 (Y-90) microspheres for unresectable primary and metastatic liver tumors. World J Surg Oncol. 2011;9(1):86-92. https://doi.org/10.1186/1477-7819-9-86.

3. Burton MA, Gray BN, Klemp PF, Kelleher DK, Hardy N. Selective internal radiation therapy: distribution of radiation in the liver. Eur J Cancer Clin Oncol. 1989;25(10):1487-91. https://doi.org/10.1016/0277-5379(89)90109-0.

4. Stephens RW, Tredwell GD, Knox KJ, Philip LA, King DW, Debono KM, et al. ${ }^{99 \mathrm{~m}} \mathrm{Tc}$-radiolabeled composites enabling in vivo imaging of arterial dispersal and retention of MS in the vascular network of rabbit lungs, liver, and liver tumors. Int J Nanomedicine. 2019;14:889-900. https://doi. org/10.2147/IJN.S187153.

5. Johnston GS, Go MF, Benua RS, Larson SM, Andrews GA, Hubner KF. Gallium-67 citrate imaging in Hodgkin's disease: final report of cooperative group. J Nucl Med. 1977;18(7):692-8.

6. Ehrhardt GJ, Welch MJ. A new germanium-68/Gallium-68 generator. J Nuc Med. 1978;19(8):925-9.

7. Schuhmacher J, Maier-Borst W. A new ${ }^{68} \mathrm{Ge} /{ }^{68} \mathrm{Ga}$ radioisotope generator system for production of ${ }^{68} \mathrm{Ga}$ in dilute $\mathrm{HCl}$-Authors' reply. Appl Radiat Isot. 1981;32(7):527. https://doi.org/10.1016/0020-708X(81)90132-0.

8. Ambe $\mathrm{S} .{ }^{68} \mathrm{Ge} /{ }^{68} \mathrm{Ga}$ generator with alpha-ferric oxide support. Int J Rad Appl Instrum A. 1988;39(1):49-51. https://doi.org/10.1016/0883-2889(88)90091-3.

9. Iffat AT, Maqsood ZT, Fatıma N. Study of complex formation of Fe (III) with tannic acid. J Chem Soc Pak. 2005;27:174-7.

10. Karamać M. Chelation of Cu (II), Zn (II), and Fe (II) by tannin constituents of selected edible nuts. Int J Mol Sci. 2009;10(12):5485-97. https://doi.org/10.33 90/ijms10125485.

11. Baynes RD, Bothwell TH. Iron deficiency. Annu Rev Nutr. 1990;10(1):133-48. https://doi.org/10.1146/annurev.nu.10.070190.001025

12. Brown SJ, Slizofski WJ, Dadparvar S. Altered biodistribution of Gallium-67 in a patient with aluminum toxicity treated with desferoxamine. J Nucl Med. 1990;31(1):115-7.
13. Broan CJ, Cox JPL, Craig AS, Kataky R, Parker D, Harrison A, et al. Structure and solution stability of indium and gallium complexes of 1,4,7triazacyclononanetriacetate and of yttrium complexes of 1,4,7,10tetraazacyclododecanetetraacetate and related ligands: kinetically stable complexes for use in imaging and radioimmunotherapy. X-ray molecular structure of the indium and gallium complexes of 1,4,7-triazacyclononane1,4,7-triacetic acid. J Chem Soc Perkin Trans 2. 1991;1:87-99.

14. Notni J, Slimecek J, Hermann P, Wester HJ. TRAP, a powerful and versatile framework for Gallium-68 radiopharmaceuticals. Chem A Eur J. 2011;17(52): 14718-22. https://doi.org/10.1002/chem.201103503.

15. Purdie TG, Henderson E, Lee TY. Functional $C T$ imaging of angiogenesis in rabbit VX2 soft-tissue tumour. Phys Med Biol. 2001;46(12):3161-75. https:// doi.org/10.1088/0031-9155/46/12/307.

16. Shelton SE, Lee $Y Z$, Lee M, Cherin E, Foster FS, Aylward SR, et al. Quantification of microvascular tortuosity during tumour evolution utilizing acoustic angiography. Ultrasound Med Biol. 2015;41(7):1896-904. https://doi. org/10.1016/j.ultrasmedbio.2015.02.012.

17. Lewis AL, Willis SL, Dreher MR, Tang Y, Ashrafi K, Wood BJ, et al. Bench to clinic development of imageable drug-eluting embolization beads: finding the balance. Future Oncol. 2018;14(26):2741-60. https://doi.org/10.2217/ fon-2018-0196.

18. Less JR, Posner MC, Skalak TC, Wolmark N, Jain RK. Geometric resistance and microvascular network architecture of human colorectal carcinoma. Microcirculation. 1997:4(1):25-33. https:/doi.org/10.3109/10739689709148315.

19. Xing F, Xun S, Zhu Y, Hu F, Drevensek-Olenik I, Zhang X, et al. Microfluidic assemblies designed for assessment of drug effects on deformability of human erythrocytes. Biochem Biophys Res Commun. 2019;512(2):303-9. https://doi.org/10.1016/j.bbrc.2019.03.066.

20. Stephens RW, Bell JL. Radiolabelled material; 2019. USA Patent 10,232,062

21. Moroz P, Jones SK, Winter J, Gray BN. Targeting liver tumours with hyperthermia: ferromagnetic embolization in a rabbit liver tumour model. J Surg Oncol. 2001;78(1):22-9. https://doi.org/10.1002/jso.1118.

22. Lee KH, Liapi E, Buijs M, Vossen JA, Hong K, Georgiades C, et al. Considerations for implantation site of VX2 carcinoma into rabbit liver. J Vasc Interv Radiol. 2009;20(1):113-7. https://doi.org/10.1016/j.jvir.2008.09.033.

\section{Publisher's Note}

Springer Nature remains neutral with regard to jurisdictional claims in published maps and institutional affiliations.

Ready to submit your research? Choose BMC and benefit from:

- fast, convenient online submission

- thorough peer review by experienced researchers in your field

- rapid publication on acceptance

- support for research data, including large and complex data types

- gold Open Access which fosters wider collaboration and increased citations

- maximum visibility for your research: over $100 \mathrm{M}$ website views per year

At $\mathrm{BMC}$, research is always in progress.

Learn more biomedcentral.com/submissions 